observing many individuals during their feeding, however, it occurred to me that they must be regarded primarily as sucking insects, rather than as biting ones. They were often seen practically motionless with their long "beaks" deeply inserted in their food substances. When they feed on insects, they first bite a hole through the chitinous skin, and then appear to suck the body fluid. It would seem probable that the long rostrum provided with biting mouth-parts at the end, so characteristic of this group of insects, is an adaptive developed in relation to these interesting feeding habits.

It may not be amiss to add, in conclusion, that the excreta of the scorpion-flies under consideration are always of liquid nature, as might be expected if they were sucking insects. In no case was there observed any solid or semisolid excrement, such as that of a biting insect.

\title{
NOTES ON THE GIPSY MOTH IN MY UNSPRAYED WOODS AT EAST MARION, MASS.
}

1922.

\section{By Fred C. Bowditch, Brookline, Mass.}

The Gipsy has been increasing in numbers for the last two seasons and I judged that this year would be the high-water mark of their infestation. My woods near the house include a grove of oaks (largely white) and another group of oaks and white pine, and various detached oaks between.

The caterpillars have the habit before pupating of bunching together, sometimes in great numbers along the trunk of the tree or under a branch. They spin a slight web and pupate in more or less of a loose mass; others in numbers of up to, say, ten or twelve, curl up in the leaves, or their remains, rather tending to keep at the ends of the branches, drawing the parts together in a loose bunch.

About the middle of June the caterpillars were very plenty and the trees began to look thin. The Calosomas (green) were 
seen running on the trees though I did not see any attacks by them on the caterpi!!ars (as observed in previous years); about the end of June the caterpillars were beginning to bunch up and I noticed at once Calosoma larvae working on them. These nearly always operated on some bunch of caretpillars on or near the trunk. The larvae were very voracious, eating constantly and increasing rapidly in size, their preference, if any, seemed to be caterpillars hunched up ready to become pupæ, because then they are perfectly helpless, almost torpid, still they constantly attacked the caterpillars and sucked out the pupæ. One small larva fastened into the rear of a full grown o caterpillar, the latter threshed about, but the larva with his legs bent up held on tght and finally the caterpillar, still threshing, began to crawl rapidly up the tree, then juice began to drop from the body of the larva. He had got his head into the caterpillar, the latter stopped and the liquid ran down the larva. Next morning the caterpillar was a dry skin.

Various diptera attended the caterpillar bunches; only one, however, was actually observed to attack. This was a grayish fly somewhat larger than the domestic, and noticeably grayish on the upper side. The fly hovered over the caterpillars, lit on one and deposited a small white object, which I could see wiggle. Calling my man, who happened to be near by, we saw this little wiggler disappear into the body of the caterpillar at about his anterior third. This caterpillar I boxed to get the fly, but the caterpillar died of wilt. In addition to the insect enemies, the caterpillars were attacked by some form of "wilt" disease, which developed tremendously when they began to bunch up. For several days I had under observation one particular bunch of about seventy-five caterpillars, mostly large females. The disease would first show in a distending of parts of the body which gradually became semi-shiny, then the vitality would seem to go out of the caterpillar, his entire viscera would become putrid, and breaking open drop out, leaving the remains hanging. This bunch of seventy-five was kept at about the same size for some days by fresh additions. Not one spun a web and only once was a Calosoma observed. They all died of disease. Just after 
the first of July we had the bunches of caterpillars, with the various enemies and disease, all working together making what my wife called"a stinking mess". Then occurred a three days storm and these messes were in spots a good deal broken up and washed down. Most of the caterpillars had pupated and the Calosoma seemed largely to have disappeared (I found one dead, quarter grown) though some of the larger still showed, sucking pupæ which they continued to do until the moths began to emerge about July 10th. By this time a great bulk of caterpillars and pupæ along the trunks etc. had been killed, the former showing partly as old skins and the latter as sucked and broken shells, but there still remained thousands to hatch, especially in the leafy bunches at the ends of the branches; with this hatching arrived our friends the birds. Our oaks were alive with them, robins gulping down some whole and gathering bunches in their mouths and carrying them off to their nests, kingbirds swooping down and picking a male fluttering near the ground as well as attending to the tops; several kinds of vireos, chickadees, various kinds of sparrows and small birds, and last but by no means least, a family of five young blackbirds with their parents. The young were very amusing . They kept up a continual chatter, following up the old birds and begging for grub, jostling each other and always all day long on the go. It would seem that the position of a blackbird parent was no sinecure. For two or three days this bird-fest kept up. It was a rare thing thing to see a male gipsy on the wing. The females on the trunks were not molested nearly as much, perhaps because they were perfectly quiet, but the fluttering males, were everywhere gobbled up. As soon as the main moth emergence was over most of the birds faded away and only a few remained to pick up stragglers.

The females begin to lay eggs almost at once. On all egg clusters that I have examined under the moth and before she has dropped off are to be seen the egg parasite, (the imported Japanese) the imago of which emerges this Fall, and which leaves the egg cluster looking like a small pepper pot with its numerous holes. 
Thus in unsprayed timber we have the various insect enemies, the "wilt" or whatever the disease is, the birds devouring imagoes and the egg parasite. I look for a distinct betterment in the outlook for 1923.

\section{SOME PARASITIC HYMENOPTERA FROM NEW ZEA- LAND. $^{1}$}

By Charles T. Brues.

Dr. R. J. Tillyard, Chief of the Biological Department of the Cawthron Institute for Scientific Research in Nelson, New Zealand, recently sent me a small shipment of parasitic Hymenoptera for indentification. Although the collection consists of only a few specimens, these are of considerable interest on account of our almost complete ignorance of the insect fauna of New Zealand belonging to these families, and I have therefore taken this occasion to report upon them, although Dr. Tillyard has promised more extensive material in the future.

All the species mentioned below are apterous or nearly so, distributed in three families, the Ichneumonidæ, Braconidæ and Belytidæ. The types are in the collections of the Cawthron Institute.

\section{Family Braconidae.}

\section{Metaspathius gen. nov.}

o Apterous. Head globular; antennæ inserted on a frontal prominence, 17-jointed, scape short and thick, pedicel moniliform; first three flagellar joints much elongated; eyes very small, round; ocelli obsolete; head margined behind; clypeus excavated, leaving a rounded mouth opening; palpi simple; slender. Prothorax elongate; mesonotum without furrows; scutellum small, narrow, shield-shaped; propodeum coarsely reticulated. Legs with the

1Contribution from the Entomological Laboratory of the Bussey Institution, Harvard University, No. 214 . 

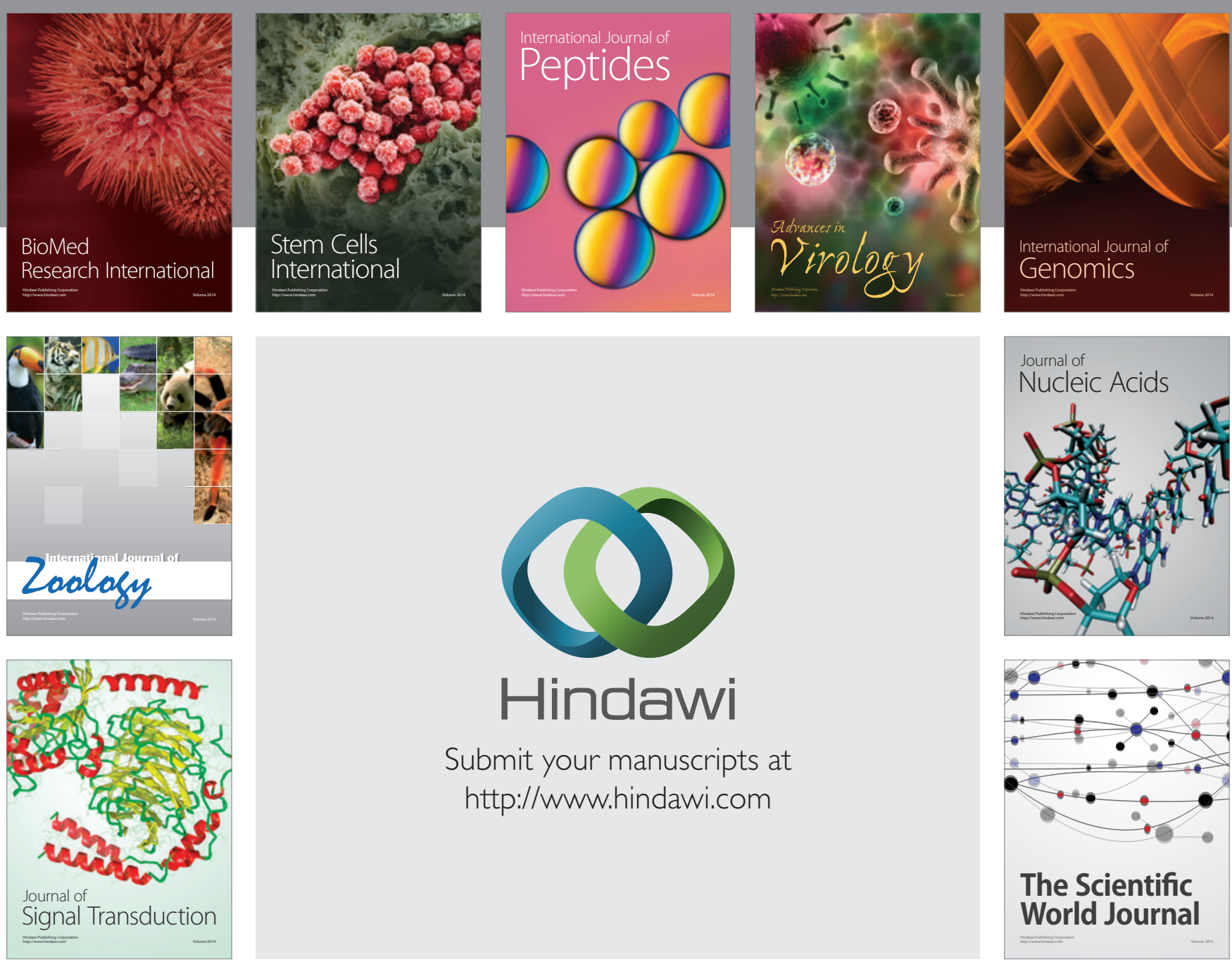

Submit your manuscripts at

http://www.hindawi.com
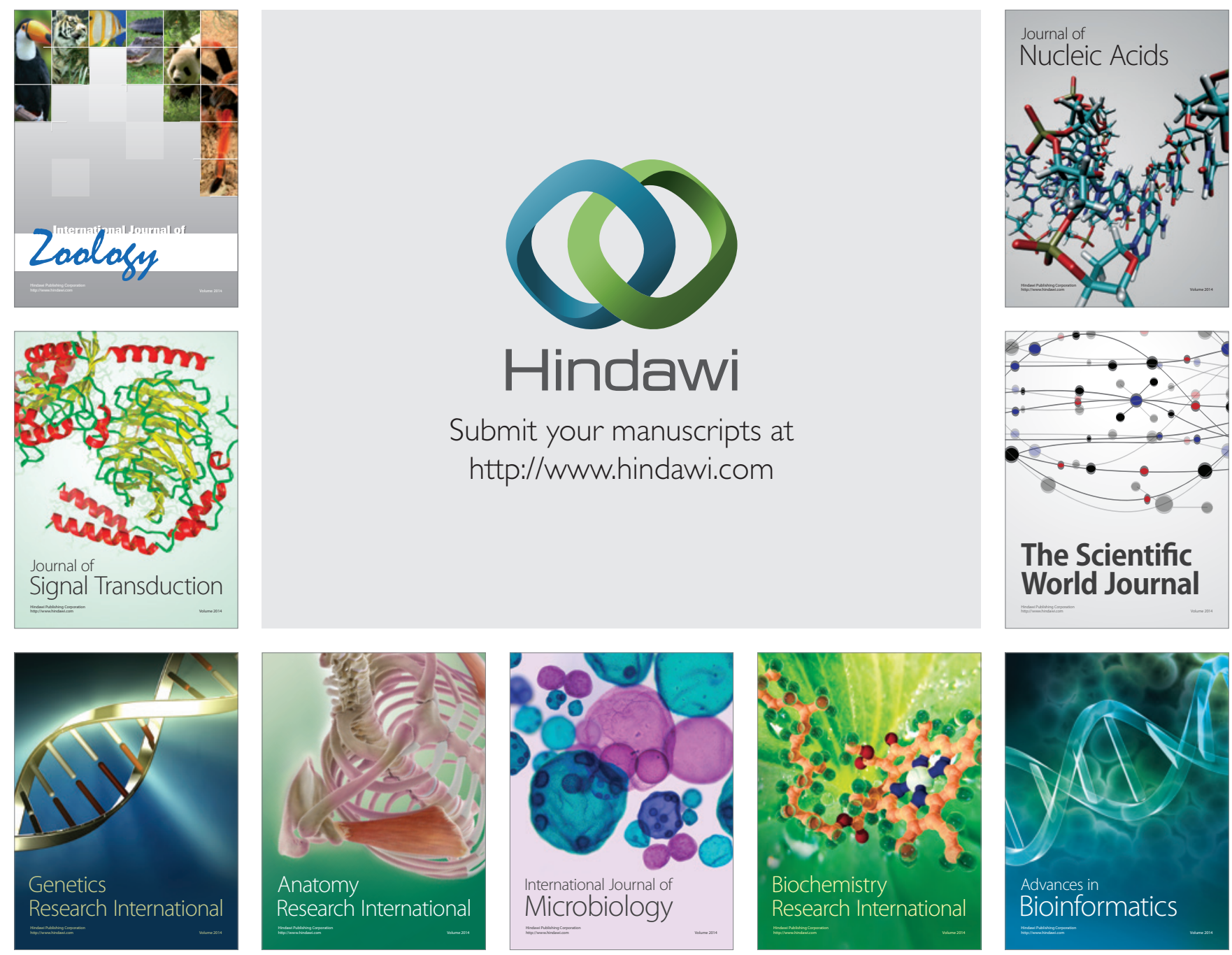

The Scientific World Journal
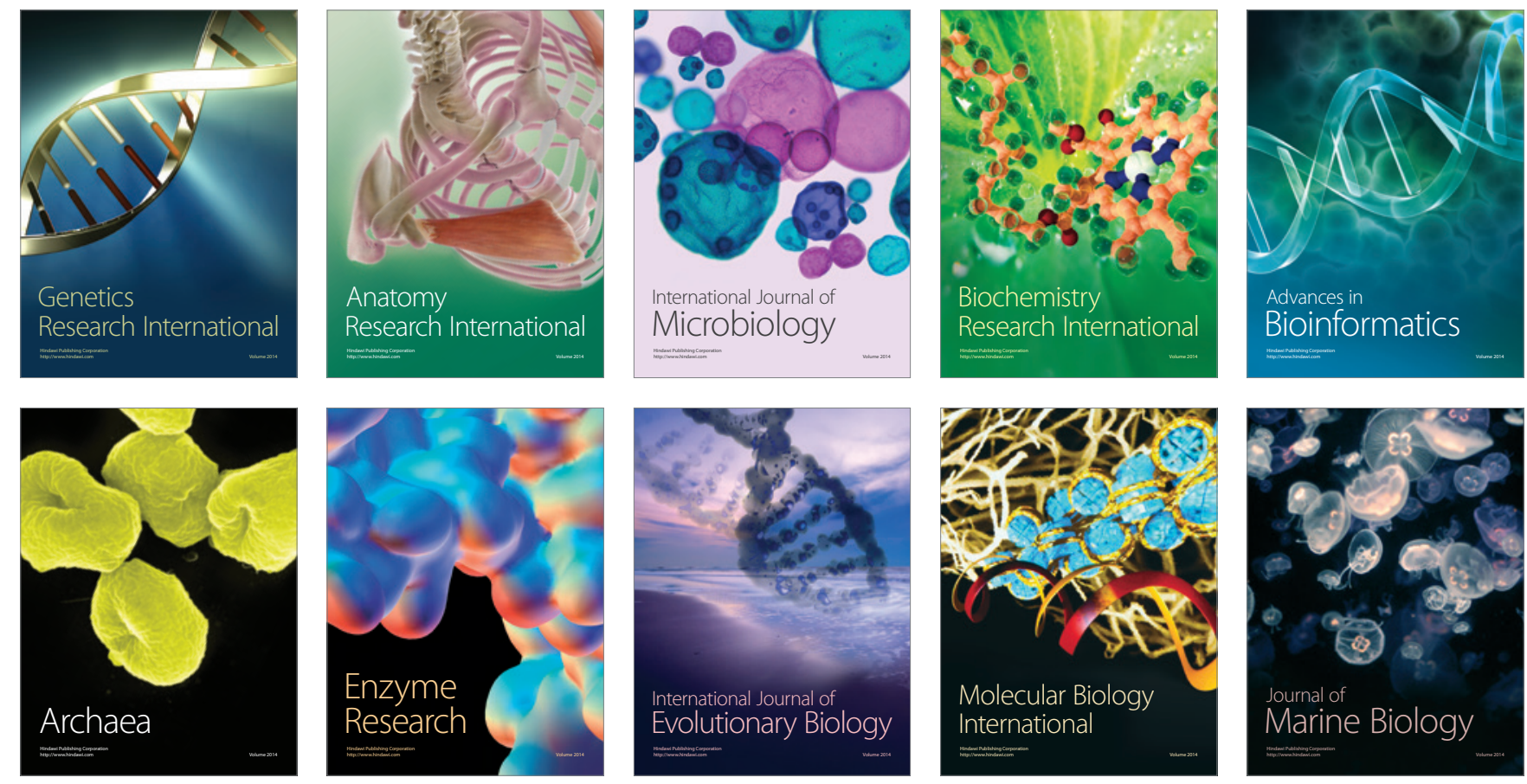